\title{
Disminución de la
}

indemnización para los hijos

por el aporte causal de los

padres en la producción

del daño y lucro cesante de

menores de edad. Análisis de

\section{la Sentencia SC-r6690 de 2016 de la Corte Suprema de Justicia*}

\section{Alejandro Gaviria Cardona*}

Resumen: La Sentencia sc-i669o de 2016 de la Sala Civil de la Corte Suprema de Justicia condenó a unas entidades médicas por negligencia en el tratamiento brindado a un recién nacido, pero, debido a que sus progenitores demoraron la búsqueda de atención médica, redujo el monto indemnizatorio al 70 \% y se abstuvo de condenar al lucro cesante por falta de certeza. Las actuaciones de los padres, frente a sus hijos, no configuran el hecho de la víctima, sino la solidaridad. Con relación al lucro cesante, es perfectamente lógico y razonable entender que, cuando cumpla i 8 años, empezará su vida productiva.

Palabras clave: Causa extraña, hecho de la víctima, reducción indemnizatoria, lucro cesante, certeza.

Fecha de recepción: 20 de junio de 2017. Fecha de aceptación: 9 de octubre de 2017. Para citar el artículo: Gaviria Cardona, A., "Disminución de la indemnización para los hijos por el aporte causal de los padres en la producción del daño y lucro cesante de menores de edad. Análisis de la Sentencia sc-r669o de 2016 de la Corte Suprema de Justicia”, Revista de Derecho Privado, Universidad Externado de Colombia, n. ${ }^{\circ} 33$, julio-diciembre de 2017,25 I-263.

DOI: https://doi.org/Io.I860I/or 234366.n33.10

** Especialista en Responsabilidad Civil y Seguros, Universidad Eafit, Colombia. Magíster en Derecho Procesal, Universidad de Medellín, Colombia. Docente universitario de las asignaturas Responsabilidad Civil y Contratos, Universidad Autónoma Latinoamericana y Eafit, Medellín, Colombia. Abogado litigante. Contacto: alejandrogaviriac@hotmail.com 


\section{The Last Interpretation of The Fact of The Victim and Its Incidence in The Liquidation of The Damage}

Aвstract: Judgment sc-r 6690 of 20 i 6 of the Civil Chamber of the Supreme Court of Justice condemned medical institutions for negligence in the treatment provided to a newborn, but, because their parents delayed the search for medical care, reduced the amount Compensatory to $70 \%$ and abstained from condemning the loss of profit for lack of certainty. The actions of the parents, in front of their children, do not configure the fact of the victim, but the solidarity. With regard to loss of profit, it is perfectly logical and reasonable to understand that, when he turns $\mathrm{I} 8$, he will begin his productive life.

KeYwords: Strange cause, fact of the victim, reduction indemnification, loss of profit, certainty.

\section{Decisión de la Corte}

En la Sentencia sc-i669o de 20i6, proferida por la Sala de Casación Civil de la Corte Suprema de Justicia el I 7 de noviembre de 2016 , se condena a unas entidades médicas por negligencia en el tratamiento médico brindado a un recién nacido ${ }^{\mathrm{I}}$.

Los hechos se pueden sintetizar de la siguiente manera: una persona en embarazo es atendida en la red de servicios de su Eps, donde, incluso, le es atendido su trabajo de parto, el cual, según se reportó en la historia clínica "no presentó complicaciones", pese a tratarse de un parto prematuro.

$\mathrm{Al}$ menor se le realizó un examen para detectar bilirrubina, el cual dio positivo; no obstante, se le dio de alta, arguyendo que la EPs de la madre no tenía convenio con la clínica en cuestión para atención pediátrica, sin que, además, se brindaran recomendaciones médicas ni se les advirtiera de las posibles secuelas.

Ocho días después de haber sido dado de alta, el menor fue llevado nuevamente por sus padres a la clínica donde nació, en donde no fue atendido, por lo que fue remitido a otro centro médico, en donde se le diagnóstico "ictericia patológica del subgrupo E. Encefalopatía bilir[r]ub[í]nica [sic]”, lo cual le generó un "retraso (...) [sic] de carácter insuperable e irreversible".

Lo anterior, entonces, llevó a que los padres del menor, tanto en nombre propio como en representación del mismo, demandaran a las entidades médicas que intervinieron en su estado de salud actual, solicitando el reconocimiento de diversos perjuicios: daño emergente por los gastos en que han incurrido y debe-

I Se aclara que no se hará mención al nombre de los sujetos procesales para protegerles su derecho a la intimidad, y en su lugar, tratándose de transcripciones, se expresará "xxx". 
rán incurrir, lucro cesante por la privación de ingresos a la que el menor se verá sometido por su lesión, así como perjuicios morales.

El juez de primera instancia condenó a las entidades demandadas al pago de perjuicios morales y concedió aproximadamente tres millones de pesos a título de lucro cesante. En segunda instancia se modificó la providencia impugnada, la cual reconoció daño emergente y revocó el lucro cesante.

Los demandantes interpusieron recurso extraordinario de casación, sentencia que finalmente fue casada debido a que no se refirió a la reclamación de los padres en representación de su hijo menor, por lo que procede la Corte Suprema a proferir la sentencia sustitutiva, pero únicamente con relación a este.

En la sentencia del tribunal quebrada por la Corte, se estableció que la demora por parte de los padres en requerir nuevamente la atención médica para su hijo, implicaba la presencia de una "culpa compartida”, razón por la cual encontraba que el aporte causal de los padres equivalía al $30 \%$, mientras que el de las demandadas ascendía al 70 \%. Aclara además la Corte que, debido a que este aspecto no fue debatido en casación, no puede pronunciarse frente al mismo, por lo que se encuentra en firme.

Expresamente indicó:

De lo expuesto se sigue, que las decisiones precedentemente comentadas, por no haber sido controvertidas por quienes tenían interés en ello, son igualmente firmes en el proceso y que, por lo mismo, resultan vinculantes, de modo que no pueden ser desatendidas por la Corte. Recapitulando, la acción es próspera y, frente a ella, sólo tiene cabida la indicada excepción, con los alcances que fijó el Tribunal, esto es, que del daño irrogado al menor son responsables, por una parte, las demandadas en un $70 \%$ y, por otra parte, sus progenitores, los esposos Campo Rosero, en un $30 \%$.

Lo cual, de conformidad con el artículo 2357 del Código Civil ${ }^{2}$, implica que el monto indemnizatorio que se llegue a reconocer deberá ser reducido de acuerdo a la participación causal de la víctima.

De otro lado, indicó la Corte que debido a la falta de certeza frente a si el menor, en el futuro, realizaría o no alguna actividad de tipo lucrativo, no condenaría al pago del lucro cesante, señalando:

La sola existencia de la persona humana, no permite aseverar que ella, en un momento dado de su vida, la mayoría de edad o cualquier otro, fuera a ser económicamente productiva y, mucho menos, calcular el monto de réditos que hubiera percibido. [...] Como ya se hizo anotar, en el escrito inaugural de la controversia,

2 Reza el artículo citado: "La apreciación del daño está sujeta a reducción, si el que lo ha sufrido se expuso a él imprudentemente". 
la única justificación que se dio en torno del lucro cesante solicitado para "xxx" fue que correspondía a "la pérdida de [su] [sic] capacidad laboral productiva", mención de la que no se desprenden bases suficientes y, mucho menos concretas, para evaluar su factibilidad y, especialmente, su extensión económica. El comentado planteamiento, por ende, se acerca más a la formulación de un mero "sueño de ganancia", que por ser hipotético o eventual, no es susceptible de resarcimiento, de lo que se sigue la improcedencia del analizado pedimento.

\section{Análisis de la postura asumida por la Corte}

En este punto se hace necesario precisar que la sentencia será abordada desde dos ópticas: la disminución de la indemnización al menor por el aporte causal de los padres (A) y la negativa a conceder lucro cesante futuro al menor (B).

\section{A. Disminución del quantum indemnizatorio}

Se tiene entonces que la Corte, al momento de cuantificar los perjuicios, aplicó una reducción del $30 \%$, toda vez que, según lo planteado en la sentencia del Tribunal, los padres demoraron la búsqueda de atención médica para el menor y, como este aspecto no fue debatido, entendió que se encontraba ejecutoriado y no podía volver sobre este.

Si bien es cierto que frente a la responsabilidad en favor de los padres no podía pronunciarse la Corporación, frente al menor tenía plena libertad.

Siendo entonces así, nada impedía pronunciarse frente a ese $30 \%$ de aporte causal imputado a los padres, quienes, se resalta, configuran un sujeto procesal diferente, configurándose de esta forma un argumento falaz. Se insiste, frente al menor tenía absoluta libertad.

Es decir, pese a que los padres sean los representantes legales del menor, ello no permite confundirlos en una sola persona, al punto de cargarle al menor las consecuencias de las conductas reprochables de sus progenitores, tal y como explicará a continuación.

Nótese cómo la decisión tiene fundamento en el artículo 2357 del Código Civil que prescribe que "la apreciación del daño está sujeta a reducción, si el que lo ha sufrido se expuso a él imprudentemente" 3 , lo cual es conocido como hecho de la víctima, que no es más que una modalidad de causa extraña 4 .

No hay duda alguna de que cuando una persona, de forma directa o personal aporta causalmente al resultado dañoso por ella sufrido, habrá lugar, bien sea a la exclusión de la responsabilidad o a la reducción del monto indemnizatorio,

3 Situación que además le es oponible a terceros reclamantes. En ese sentido ver TAmayo Jaramillo, J., Tratado de Responsabilidad Civil, t. II, Bogotá, Legis, 2007, 72-8I.

$4 \quad$ Ibid., I6.

Revista de Derecho Privado, n. ${ }^{\circ}$ 33, julio - diciembre de 2017, pP. 251 a 263 
dependiendo del grado de aporte causal. Esta posición, además de sana es lógica, toda vez que "el principio de autorresponsabilidad implica entonces que el damnificado debe asumir las consecuencias de su propio accionar"5.

Cuestión diferente cuando no es la víctima directamente quien ocasiona su daño.

Para un adecuado análisis de la situación presentada, deberemos diferenciar dos situaciones: una cosa es que el hecho de la víctima provenga de las personas que están bajo su cuidado o subordinación, por ejemplo, cuando es causado por sus hijos o dependientes, y otra, muy diferente, cuando el hecho es ocasionado por aquel que controla o dirige las actuaciones de otra persona, como, por ejemplo, el padre.

La consecuencia no podrá ser igual para ambos eventos. Si el hecho de la víctima es causado por una persona que se encontraba bajo su cuidado o subordinación, la norma que debe ser aplicada, sin duda alguna, es el 2357 del Código Civil, toda vez que se entiende que la víctima aportó causalmente a su resultado dañoso al permitir que su subordinado o dependiente causara el daño, o que la actuación del dependiente es la misma actuación de la víctima, lo cual, tal y como se indicó, implicará bien sea la reducción de la indemnización o su exclusión, atendiendo que "si el hecho de la víctima (aunque sea un inimputable) tuvo una vinculación causal con la producción del daño, es evidente que para el dañador se trata de una causa ajena por la cual no debe responder"6.

Es importante precisar entonces quién es la víctima. Es el sujeto a quien se le causa una lesión, bien sea a su integridad corporal, a sus bienes o de forma inmaterial. En términos generales se puede afirmar que existen dos clases de víctimas: la directa, que es quien sufre el daño de forma personal, y la indirecta que, si bien no sufre el daño, sufre perjuicios derivados del daño de la víctima directa 7 .

Luego, podremos entender que realmente estamos frente a un hecho de la víctima cuando el daño ha sido causado, en todo o en parte, bien sea por la víctima (directa o indirecta), o por las personas por las cuales la víctima está llamada a responder.

Precisamente, el artículo 2347 del Código Civil ${ }^{8}$ establece la denominada responsabilidad por el hecho ajeno, en la cual, una persona tiene la obligación

5 Trigo Represas, F. A. y López Mesa, M. J., Tratado de la responsabilidad civil, t. v, Buenos Aires, La Ley, 2004, 693.

6 Ghersi, C., Teoría general de la reparación de daños, Bogotá y Buenos Aires, Universidad del Rosario y Astrea, 2013, I 56-I 57. En ese mismo sentido, Mazeaud, H. y Mazeaud, L., Elementos de la Responsabilidad Civil, Bogotá, Leyer, 2005, 492, quienes expresan que "cada cual debe sorportar el perjuicio en la medida en que lo haya ocasionado. Este sistema tiene el gran mérito de colocar el problema en su verdadero terreno: el del vínculo de causalidad".

7 Gaviria Cardona, A., Guía teórico-práctica para la cuantificación de perjuicios, Medellín, Fondo Editorial Universidad Eafit, $2017,22$.

8 Reza el artículo citado "Toda persona es responsable, no solo de sus propias acciones para el efecto de indemnizar el daño, sino del de aquellos que estuvieren bajo su cuidado [...]". 
de responder por las actuaciones de otra que se encontraba bajo su cuidado o subordinación, lo cual acontece en la primera hipótesis señalada. Luego, "la idea general que guió a los redactores del precepto transcrito es la siguiente: la patria potestad impone a los padres obligaciones no solo respecto del hijo, sino también respecto de tercero; los padres deben, dando a sus hijos buena educación y vigilándolos atentamente, impedirles que causen algún perjuicio"9, razón por la cual, "mientras que los hijos menores no hayan alcanzado la mayoría de edad, los padres deben responder por las consecuencias que el actuar ilícito de aquéllos pudiere ocasionar a terceros" "

Por el contrario, si el evento dañoso fue ocasionado a un pupilo por quien lo tenía bajo su cuidado o subordinación, no podrá invocársele a la víctima el referido artículo 2357 del Código Civil, atendiendo que no existe ninguna razón para proyectar el alcance de su actuar como una actuación de la víctima en sí, toda vez que esto nos llevaría a situaciones complejas. Piénsese por ejemplo en un hecho realizado por un empleador. Si acogiéramos la postura de la Corte, se entendería que el hecho del empleador, frente a su trabajador, configura un hecho de la víctima, por lo que del monto indemnizatorio debería reducirse de acuerdo al grado de participación causal, o, incluso, excluirse. Igual ocurriría frente al hecho de los padres, el cual, con relación a sus hijos, constituiría un hecho de la víctima.

La decisión que se viene analizando de la Corte incurrió en el error de entender que el hecho del "superior" se extiende a sus dependientes o subordinados como hechos de la víctima, siendo que estos no tienen ningún control frente al hecho de aquel.

Luego, si el hecho es cometido por alguien diferente a la víctima o a las personas que esta tenía bajo su cuidado o dependencia, no podrá invocarse la existencia de un hecho de la víctima, sino que ese sujeto dañador será responsable frente a la víctima, toda vez que las personas sólo están obligadas a responder por sus propias actuaciones o de las de aquellos que tienen bajo su cuidado o dependencia ${ }^{\text {II }}$.

Ahora, si se trata de diversas personas aportando causalmente al resultado dañoso, no se puede desconocer, asimismo, que el artículo 2344 del Código Civil

9 Mazeaud y Mazeaud, op. cit., 22 I. En este mismo sentido, Le Tourneau, P., La responsabilidad civil, Bogotá, Legis, 2010, I 55, expresa que "la responsabilidad de los padres solo [sic] ha sido establecida en interés de la víctima".

GHersi, op. cit., 329.

Reglero Campos, L. F. y Medina Alcoz, L., "El nexo causal. La pérdida de oportunidad. Las causas de exoneración de responsabilidad: culpa de la víctima y fuerza mayor", en RegLero Campos, L. F. (coord.), Tratado de responsabilidad civil, Navarra, 2008, en donde se indica que "si la víctima fuera imputable, tal circunstancia sería deci-siva [sic] para exonerar de responsabilidad al dañante. Si no lo es, debe éste [sic] indemnizar, a no ser que, en el caso concreto, aquélla hubiera buscado deliberadameente el daño, hubiera provocado la situación de riesgo 0 , en ciertos casos, el daño pueda ser subjetivamente imputable a un tercero sobre el que pesa un deber de control y vigilancia del inimputable”. (Cursiva fuera del texto original). 
establece la responsabilidad solidaria en eventos de pluralidad de responsables: "Si un delito o culpa ha sido cometido por dos o más personas, cada una de ellas será solidariamente responsable de todo perjuicio procedente del mismo delito o culpa $[\ldots] "$.

Nótese que esta norma establece que si el evento dañoso tiene diversos responsables, frente a la víctima, todos son solidariamente responsables. Esta regulación no tiene en cuenta ninguna situación adicional, como, por ejemplo, el grado de cercanía o parentesco entre el responsable y la víctima. Es decir, basta que el evento dañoso haya sido causado por dos o más personas para que entre ellos exista solidaridad con relación a la víctima, siendo irrelevante si el responsable es familiar cercano, por ejemplo, el hermano o esposo de la víctima, o su empleador, debido a que, se insiste, frente a ella, habrá solidaridad entre todos los responsables.

Por tanto, la circunstancia de que a la producción del daño haya concurrido otro sujeto responsable (o bien, otros sujetos responsables), no alivia, al autor del daño, ni siquiera parcialmente, de su responsabilidad, ya que, la constatación de esta circunstancia hace que la responsabilidad se asiente en el valor determinante del hecho realizado. El hecho concurrente de otro sujeto responsable es irrelevante acerca de la entidad del daño resarcible, al igual que cualquier otro hecho que concurra, siempre que no sea del propio perjudicado. La diferencia está en que el hecho concurrente de otro sujeto responsable produce, a su vez, a cargo de aquel sujeto, la obligación de resarcir; pero la responsabilidad de cada uno es íntegra, al estar cada uno obligado solidariamente al resarcimiento; por consecuencia, la entidad del daño, que cada uno debe resarcir, no está de facto disminuida por razón de la concurrencia de los demás ${ }^{\mathrm{I} 2}$.

Se itera, no importa el vínculo familiar, ni la cercanía entre la víctima y el responsable, siempre que varias personas sean causantes del daño, entre ellas habrá solidaridad y no podrá invocarse el hecho de la víctima cuando esta actuación provenga de alguien cercano a ella; por ejemplo, de los padres de la víctima.

Ahora, recuérdese que uno de los efectos de la solidaridad implica que el acreedor es libre de escoger a cuál o cuáles deudores demanda, lo cierto es a quien elija deberá sufragarle el ciento por ciento del monto indemnizatorio.

Se tiene entonces que es perfectamente lógico hacer que los padres respondan por las actuaciones de sus hijos menores (o que los empleadores respondan por los hechos de sus trabajadores), siendo que estos están subordinados frente a aquellos, pero a la inversa, el asunto ya no es tan claro, toda vez que los padres gozan de absoluta libertad para actuar frente a sus hijos; es decir, no existe ninguna clase de argumento ni legal ni fáctico que permita extender la actuación de los 
padres frente a sus hijos, atendiendo que "el hecho de la víctima no puede tenerse en cuenta sino a condición de que tenga un vínculo de causalidad con el perjuicio. Nada importa la intervención, ni aun culpable de la víctima, cuando nada ha tenido que ver en la realización del perjuicio" ${ }^{13}$, es decir, sólo cuando la actuación de la víctima (o de las personas que están bajo su cuidado) aporta causalmente al resultado al evento dañoso, podemos afirmar que estamos en presencia de la causa extraña denominada hecho de la víctima, lo cual no ocurrió en el presente caso, por lo que extender la regla y hacer responder a los hijos por las actuaciones de sus padres, además de ilógico, es insostenible desde todo punto de vista.

En el caso bajo estudio, la decisión de la Corte debió ser la imposición, de forma solidaria, de indemnizar al menor por el ciento por ciento ( го० \%) de sus perjuicios, atendiendo que el evento dañoso fue ocasionado por diversas personas, aunque, debido a que sólo se demandó a las entidades médicas, debieron ser estas las llamadas a sufragarla.

Precisamente, fue esta la posición asumida por la magistrada Margarita Cabello Blanco, quien salvó parcialmente su voto:

En consecuencia, al haber deducido el sentenciador ad quem una corresponsabilidad de los padres y las demandadas, a estas hubo de condenarlas a favor de aquellos en el porcentaje del total de los daños que encontró reclamados y acreditados, en eventual aplicación del artículo 2357 y con olvido de las pretensiones del menor, en relación con el cual el asunto es diferente: él es, repito, la víctima directa y son, de acuerdo con esa parte de la decisión del Tribunal, los padres y las demandadas sus autores, unos en el $30 \%$ y otros en el $70 \%$, pero respecto de él, tales proporciones en la incidencia causal del daño que padece distribuciones son diferentes. En efecto, estimo que como lo que es objeto de resolución complementaria debido al fallo diminuto del Tribunal, son las pretensiones del menor dirigidas contra demandadas, debe partirse del hecho de que, según el artículo 2344 del Código Civil "Si de un delito o culpa ha sido cometido por dos o más personas, cada una de ellas será solidariamente responsable de todo perjuicio procedente del mismo delito o culpa" [...] Por lo que si el menor sólo demando a las entidades de salud, ellas son solidariamente responsables del total del perjuicio irrogado a aquel.

\section{B. Lucro cesante}

De otro lado, recuérdese que, tal y como se anotó, la Corte niega el lucro cesante futuro sobre el menor demandante, arguyendo que no hay certeza sobre el mismo. 
Le lesión sufrida por el menor demandante le ocasionó graves secuelas en su integridad corporal (física y mental), a tal punto que siempre dependerá de otra persona, no sólo para su sustento económico sino, además, para el normal desarrollo de su vida diaria.

La posición asumida por la Corte parece olvidar que la afectación del menor le impedirá desarrollarse laboral y productivamente, es decir, dada la lesión causada a la víctima, esta no podrá desempeñar ninguna labor de tipo lucrativo, desconociendo, entonces que "En caso de disminución de la integridad psicofísica (y, muy especialmente, de graves incapacidades), cabe admitir el resarcimiento a título de daño patrimonial, a pesar de que la víctima no tuviese ocupación remunerada o no hubiese perdido su empleo" I4, lo cual implica que "la integridad de una persona tiene, de por sí, un valor por su repercusión presente y futura y, en el caso de personas jóvenes, aquélla constituye un capital potencial, destinado a ser normal fuente de beneficios. Disminuido el mismo, tal circunstancia se proyectará en el futuro, restando posibilidades reales, probabilidades de éxito, que es forzoso indemnizar" 15.

Los magistrados Ariel Salazar Ramírez y Luis Armando Tolosa Villabona aclararon y salvaron su voto, respectivamente, y expresaron:

No es posible, por tanto, seguir asumiendo el criterio que esta Sala acogió en el pasado acerca de la improcedencia de conceder la indemnización por lucro cesante futuro a menores de edad por el simple hecho de no estar devengando un salario en la fecha de la ocurrencia del hecho dañoso; pues la indemnización integral, equitativa y efectiva de los daños no busca poner a la víctima en la situación exacta en que 'se hallaba' antes del daño, sino en la posición en que 'habría estado' de no ser por la ocurrencia del hecho dañoso antijurídico. Es decir que la tasación de este rubro no se hace con base en "certezas" sino que hay que tener en cuenta la situación futura más probable a partir de la condición presente que se probó en el proceso ${ }^{\mathrm{I}}{ }^{6}$.

Es decir, en el estado actual de cosas, si bien no se podrá establecer con absoluta certeza la configuración del lucro cesante futuro, lo más probable es que el menor, al alcanzar su mayoría de edad, empezaría a desarrollar una actividad

I4 Sentencia cnciv, Sala B, 28/ I I/97, causa B2 2 I 582 , Jurispr. Cám. Civ., Isis, sum. oo I o6o5, citada por Tanzi, S., Rubros de la cuenta indemnizatoria de los daños a las personas, Buenos Aires, Hammurabi, 201 I, 70.

I 5 Ibid.

I6 Aclaración de voto del magistrado Ariel Salazar Ramírez. 
cualquiera de tipo lucrativo, la cual, obviamente, ya no podrá llevar a cabo, razón por la cual, el responsable debió ser cargado con esta indemnización ${ }^{\mathrm{17}}$ :

Según la experiencia de hoy en día no hay nada de incierto en anticipar con un alto grado de probabilidad científica que una persona a la que le han cercenado por completo todas las posibilidades de valerse por sí misma no podrá desenvolverse en el mercado laboral cuando alcance su edad adulta, no podrá desempeñar ninguna actividad económica y no tendrá ninguna posibilidad de obtener por sí misma los ingresos necesarios para su congrua subsistencia; sin que exista un motivo para que los padres, familiares o terceras personas asuman una obligación dineraria que corresponde a la entidad generadora de las lesiones graves que sufrió el menor ${ }^{18}$.

En otras palabras:

De no haber sido alterada la existencia de la víctima, en el futuro habría obtenido un ingreso, como consecuencia de haberse mantenido intangible o inalterada la corporeidad o la integridad física. De no haberse verificado la conducta antijurídica o el hecho dañoso habría podido obtener una ventaja, utilidad o salario. El hecho dañoso, [sic] frustra y trunca una posibilidad futura de laborar [...] Sin duda, un daño malogra una expectativa probable indemnizable, no eventual ni subjetiva o de meras aspiraciones como ocurriría en el daño eventual, sino como capacidad real para laborar. Por tanto, el reconocimiento del lucro cesante futuro para una persona, así sea menor de edad, no es un don gracioso del Estado ni de sus jueces, sino un derecho que pertenece a la propia mismidad del ser humano, por cuanto es y ha sido el trabajo humano el que ha forjado al hombre como humano, como uno y singular, entre todos los otros seres vivos de la tierra ${ }^{19}$.

Ahora, que no afirmen que no es posible cuantificar el perjuicio porque no hay una base de ingresos sobre el cual liquidarlos, toda vez que en asuntos judiciales, a falta de prueba de ingresos se cuenta con diversos mecanismos ${ }^{20}$ : equidad, prueba de gastos, ingresos de personas que desarrollen la misma actividad, e incluso, acudir al salario mínimo, atendiendo que "cuando se alega la pérdida de

i Trigo Represas y López Mesa, op. cit., quienes indican que "el mecanismo, entonces, para cuantificar el lucro cesante consiste en un cálculo sobre lo que hubiera ocurrido, de no existir el evento dañoso [...] la pauta para juzgar si el lucro cesante es resarcible o no la da el curso normal y ordinario de las cosas; si normalmente era probable que el lucro se efectivizara, el daño será resarcible, no siéndolo en caso contrario"

I 8 Aclaración de voto del magistrado Ariel Salazar Ramírez.

I9 Salvamento parcial de voto del magistrado Luis Armando Tolosa Villabona.

20 Tamayo Jaramillo, op. cit., 91 7-9i 8. 
ganancias no puede exigirse una certeza absoluta, siendo suficiente la probabilidad de que la víctima las bubiere percibido en caso de no ocurrir el acto ilícito" ${ }^{2}$, es decir, siendo razonable que las personas son laboralmente productivas, y que al alcanzar su mayoría de edad empezarán a obtener algún tipo de ingreso por ejercer actividades de tipo lucrativo, es razonable entender, en atención a la probabilidad, que el acto ilícito que recae sobre un menor, le ocasionará lucro cesante al cumplir I 8 años.

Luego, es sobre este ingreso que se calcularía el lucro cesante, el cual no podría ser consolidado sino solamente en el futuro, pero sólo desde que adquiere la mayoría de edad, al que, además, deberá realizársele un descuento por el pago anticipado $^{22}$ : nótese que el perjuicio sólo se causará en el momento en el cual el menor deje de serlo, pese a lo cual el responsable lo pagará con antelación, lo que implicará descontar los intereses sobre ese periodo de tiempo que falte para cumplir los r 8 años.

Precisamente, de antaño el Consejo de Estado colombiano ha sostenido:

Parece incuestionable, por razones de justicia, predicar que cualquiera que sea la edad de la víctima, y aunque no esté laborando en el momento del accidente, ella tiene derecho a que se le indemnice a título de lucro cesante, la pérdida o disminución de la posibilidad que tenía de ganarse la vida en una actividad lucrativa. Lo razonable parece ser que si el daño ocurre, llegado el momento en que la persona tiene plena capacidad laboral, se le reconozca la indemnización correspondiente por las condiciones inferiores en que queda la víctima, en relación con las que tenía antes de ocurrir el accidente ${ }^{23}$.

\section{Conclusiones}

Para que verdaderamente se configure el hecho de la víctima como causa extraña, se requiere que el hecho provenga o directamente de la víctima o de las personas que esta tiene bajo su cuidado o subordinación.

El supuesto no aplica para eventos en los cuales el evento dañoso se causó (o hubo aporte causal) por la persona que tenía bajo su cuidado a otros, como, por ejemplo, los padres o empleadores, siendo que, en estos supuestos, estos estarán

2 I TANZI, op. cit., 3 I 2.

22 Gaviria Cardona, op. cit., I40-I42.

23 Sentencia del r6 de marzo de r989 de la Sección Tercera del Consejo de Estado, consejero

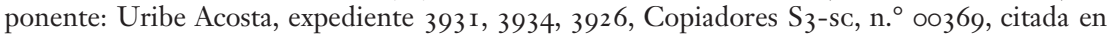
Henao, J. C., El Daño. Análisis comparativo de la responsabilidad extracontractual del Estado en derecho colombiano y francés, Bogotá, I998, p. I72. Igualmente, el autor referencia las sentencias del 8 de marzo, consejero ponente: Suéscun, expediente 2554 (ver p. I 72 ) y del I 5 de enero de I 995 (ver p. 2 I 6), consejero ponente: Carrillo Ballesteros, expediente ı 9986, ambas de la Sección Tercera del Consejo de Estado. 
llamados a responderle a la víctima, y si son varios los responsables, entre ellos habrá solidaridad, tal y como lo prescribe el artículo 2344 del Código Civil.

Si bien los perjuicios deben ser ciertos, en algunos eventos no es posible encontrar una certeza absoluta, por ejemplo, en los perjuicios futuros, caso en el cual se recurre a un grado de probabilidad.

Tratándose del lucro cesante sobre menores de edad, pese a que no lo sufren inmediatamente, atendiendo que no se encuentran devengando ningún tipo de ingreso, no hay duda de que al alcanzar su mayoría de edad, estos se hubiesen convertido en personas económicamente productivas, razón por la cual este perjuicio debe serles reconocido, pero, se insiste, sólo desde que cumplen r 8 años, aunque, se aclara, debido al pago anticipado, deberá realizarse, sobre la suma a reconocer, un descuento financiero.

\section{Bibliografía}

De Cupis, A., El Daño. Teoría General de la Responsabilidad Civil (Á. Martínez Sarrión, trad.), Barcelona, Bosch, I975.

Gaviria Cardona, A., Guía teórico-práctica para la cuantificación de perjuicios, Medellín, Fondo Editorial Universidad Eafit, 20 I 7.

Ghersi, C. A., Teoría general de la reparación de daños, Buenos Aires y Bogotá, Astrea y Universidad del Rosario, 20I3.

Henao, J., El Daño. Análisis comparativo de la Responsabilidad Extracontractual del Estado en Derecho Colombiano y Francés, Bogotá, Universidad Externado de Colombia, I998.

Le Tourneau, P., La Responsabilidad Civil (J. Tamayo Jaramillo, trad.), Bogotá, Legis, 20 Iо.

Mazeaud, H. y Mazeaud, L., Elementos de la responsabilidad civil, Bogotá, Leyer, 2005 .

Reglero Campos, L. F. y Medina Alcoz, L., "El nexo causal. La pérdida de oportunidad. Las causas de exoneración de responsabilidad: culpa de la víctima y fuerza mayor". En L. F. Reglero Campos, Tratado de Responsabilidad Civil. Parte General, vol. I, Navarra, Thomson Aranzadi, 2008.

Tamayo Jaramillo, J., Tratado de Responsabilidad Civil, Bogotá, Legis, 2007. 
TanzI, S. Y., Rubros de la cuenta indemnizatoria de los daños a las personas, 2." ed., Buenos Aires, Hammurabi, 20 I I.

Trigo Represas, F. A. y López Mesa, M. J., Tratado de la Responsabilidad Civil, Buenos Aires, La Ley, 2004. 